\title{
Research into some factors which influence the vertical loading of railway track
}

\author{
by \\ J. C. Loach, M.Sc., A.M.I.C.E.
}

Dr R. D. Davies (Reader Emeritus, Cambridge University Engineering Department) thanked the Author for a very useful Paper which would be welcomed by all those who had worked in this tricky field.

38. He would confine his remarks to the case of the four-wheeled brake van (Fig. 8). The results at both joints (7 and 17) broadly confirmed that the division of the total load into 'sprung' and 'unsprung' was unimportant. A possible explanation of this surprising conclusion was as follows. There never was any sprung load because the large static dry friction between the leaves of the springs was never broken, and the springs therefore acted as rigid bars. This behaviour of leaf springs was noticed by the Bridge Stress Committee some 40 years ago. ${ }^{2}$

Mr C. L. Fouvy (Assistant Engineer, Melbourne and Metropolitan Tramways Board, Australia) said that he was pleased to find that Mr Loach's Paper contained precise information about the vertical loads on, and deflexion of, railway tracks. The information was valuable for tramway as well as railway engineers.

40. The equipment described for measuring vertical rail loads and deflexions showed that there no longer need be guesswork in this field. Provided that they were available, the load measuring baseplate and apparatus for measuring the stiffness of track beds could be applied to any problem of this nature.

41. The results of tests carried out by the Author and quoted in his Paper provided much useful information about the behaviour of ballast tracks under various types of wheel loads.

42. The first conclusion that 'any advantage to be gained on the track from fullysprung electric motors instead of axle-hung motors is negligible' was of considerable help to any evaluation of the type of electric motor to be used in tramcar bogies. It showed, for example, that the advantages of using fully-sprung electric motorsan important feature of the 1935, and later, Presidents' Conference Committee (PCC) Tramcar Bogies-were less vibration shock to the motors; ease of maintenance; and that smaller, higher speed motors could be used than were possible with the type of drive and limited gear ratio associated with axle-hung motors.

43. The second conclusion, that "the magnitude of the maximum vertical load which the wheel imposes on the rail is primarily influenced by speed and the stiffiness of the track bed rather than by the amount of unsprung weight carried by the wheel', had an important bearing both on the design of tracks and on the advantages to be gained from the use of resilient wheels.

44. The first consideration which this second conclusion suggested was that, from the point of wear and tear on the track, the total wheel loads were what mattered.

- Proc. Instn civ. Engrs, vol. 30, April 1965, pp. 731-746. 
The reduction of unsprung weight at the wheels, by means of resilient wheels OR fully-sprung instead of axle-hung motors, therefore had little or no influence on track wear because it was the total and not the unsprung wheel load that was transmitted from wheel to rail at their point of contact. Rather, higher speeds and higher stiffness of the track bed (or rail support) caused greater track wear. Since higher speeds were usually necessary, track wear could be reduced by using a more resilient rail support. Mr Loach quoted the stiffness of a railway ballast track as varying from 100 ton/in. for new track to 200 ton/in. for older track with well-compacted ballast. By contrast, the stiffness of the Melbourne and Metropolitan Tramways Board's standard CSS (concrete-to-street-surface) track with rail completely supported in concrete was estimated as being at least 1000 ton/in. because of the incompressibility of the concrete rail support. Compared with this the stiffness of a specially designed 'resilient concrete' track was determined by test as 94 ton/in., a stiffness similar to that for ballast tracks. In this resilient track design, a $\frac{1}{2}$-in. thick fluted rubber rail pad (vulcanized natural rubber of $40^{\circ}$ BS \& IRH) was placed as a continuous stringer support between the rail base and the concrete foundation.

45. The second consideration concerned the use of resilient wheels, in that their use, contrary to present opinion, was considered not to reduce wear and tear on the track thought they might reduce it elsewhere. Their chief advantages would therefore seem to be

(a) an increase in the amount of spring equipment on bogies (e.g. bearings, gears, and motors) with a consequent reduction of their wear and tear due to vibration, and

(b) a reduction of wheel-on-rail impact noise at rail joints, points, and crossings.

46. Mr Loach was to be commended for his experimental work and the results and conclusions arising from it. So far, his recorded experiments had been confined to the influence of unsprung wheel weight and stiffness of the rail support on the vertical load on the track. Extension of these experiments to include other variables such as roughness of wheel tread and rail surfaces, and to include other equipment such as a sound level meter would appear to be well worth while. The results of these further experiments would then furnish answers to such other important questions as

(a) what was the effect of surface irregularities such as rail corrugations and wheel flats on vertical wheel loads when train speed and degree of surface roughness were varied;

(b) what was the relation between these vertical wheel loads and wheel-on-rail noise; and

(c) if there was a regular and predictable relation between wheel loads and noise (when measured under strictly specified conditions), could a sound level meter be more readily used to measure loads than the special baseplates?

Mr G. G. Kibblewhite (Electrical Engineer (Rolling Stock) British Railways Board) wrote that the Author had in the main dealt with the effect of axle-hung motors compared with spring borne motors on the track. The particular motors were rated at $1000 \mathrm{~h}$.p. with a weight of $\mathbf{4 \cdot 2}$ tons and as far as observations could be made there was little detrimental effect on the traction motor itself. Observations of commutation in service were not possible but after 5000 miles' operation, no difference could be detected in the conditions of the machines with the alternative method of suspension.

48. Acceleration measurements were made on the top brush box and it was found that the magnitude increased from about $2 g$ to $6 g$ with the axle-hung motor but it was considered that this was not abnormal and could be taken care of in the design of the brush gear.

49. The deltic locomotives with 2-3 motor bogies and lighter motors operated at speeds of $100 \mathrm{mile} / \mathrm{h}$, and no indication had been found here that the motors suffered 
any harm from being axle hung. He was fully aware that it was not possible to apply results for a $C_{0}$ bogie to a $B_{0}$ but this was corroborating evidence. With the spring mounted motor, the primary suspension springing had to be limited to the clearance between the axle and the quill and in the case of these particular locomotives was $1 \frac{1}{\mathrm{~g}}$ in. whereas with the axle hung motors the primary springing maximum movement was increased to 2 in.

50. The evidence obtained from the tests and subsequent observation as the conditioned machines had lead British Railways to adopt the axle-hung motors for their new BB locomotives thereby saving some $£ 5000$ per locomotive but the final evidence to justify this decision would have to wait until the end of 1966 following service experience with the fleet.

Mr W. E. Gelson (Sir Bruce White, Wolfe Barry \& Partners) wrote that the elegant design of load cell used in conjunction with multi-channel recording equipment had provided a valuable tool for experiments.

52. Track investigations undertaken by the Indian Railway Board between 1936 and 1938, included measurements of rail deflexions under multiple unit electric suburban stock of similar characteristics to the suburban trains originally built for the Liverpool Street/Shenfield electrified section of British Railways. The results of the tests were reported in Track Stress Research Progress Report, Volume 2, published by the East Indian Railway Press in 1939. In the series for a 'low joint' on page 92, the variation of deflexion with speed was of a similar order to those for maximum vertical loads for Bo-Bo locomotives given in the Paper, within the range of the tests which were made up to $46 \mathrm{mile} / \mathrm{h}$.

53. With rail vehicles, there was usually a continuously varying transfer of load from one wheel to the other in a wheel pair at speed due to rolling and there were also variations in axle load due to pitching and vertical oscillations. It would appear that load cells would have to be applied to rather more than the six adjacent sleepers used by $\mathrm{Mr}$ Loach in order to separate the various effects. Influence lines for depression and load could not be assumed to be symmetrical at joint or shoulder sleepers on account of the discontinuity introduced by a joint. Would the Author explain the procedure for determining the effects of an adjacent axle when spaced close enough to influence the axle under test?

54. The method of determining the static stiffness of track beds described in $\$ 26$ and illustrated in Fig. 9 would seem to lead to values considerably greater than the truth, on acount of ballast consolidation by adjacent sleeper loads. Mr Loach stated that the method was used in the experiments reported by Professor Inglis in his Paper. ${ }^{1}$ An explanation now appeared for the very high values of ballast stiffness assumed by Professor Inglis which were commented upon by Mr Gelson in the discussion on that Paper.

55. The rail joints used in the experiments described in the present Paper were 'open spaced'. Such joints introduced a greater discontinuity than when the joint sleepers were closed up by retaining 4-hole fish plates. Each axle made a larger vertical excursion than it would do with close space joint sleepers and because of the greater distance travelled, the rotational speed of each wheel pair must increase and decrease when running over joints. At high speeds this could not be fully realized and slipping occurred. The larger the rotational inertia in the wheels, axles, gearing, and armature of nose suspended motors, the more slipping occurred, which resulted in wear, pounding and flow of the head, such as depicted in Fig. 13 of the Paper. An effect of closer spacing of joint sleepers was to reduce the vertical excursion of axles and give longer rail life.

The Author, in reply to Dr Davies, agreed that, in all probability, the laminated springs of the four-wheeled brake van were acting as solid bars: the hysteresis loops 
obtained during load-deflexion tests on similar springs were usually very wide indeed, indicating the large amount of friction in them. However, even if the springs worked relatively freely, the deflexion-rate was necessarily small so that the sprung mass closely followed the vertical movements of the unsprung mass; and it was the Author's opinion that the conditions most conducive for this to happen occurred when twoaxle units were travelling over depressions in the two rails which were opposite to each other, for example over joints in British railway track. It was admitted, however, that the results obtained from three-axle units in similar conditions were not measurably different.

57. It was gratifying to learn from Mr Fouvy that the information in the Paper was helpful in assessing the merits of different electric motor suspensions. In confirmation of results given in the Paper it might be of interest to mention that some tests had been made more recently by running Bo-Bo electric locomotives (two having fully suspended motors but different flexible drives and the third having axle-hung motors but otherwise all similar) over the same joints instrumented with the loadmeasuring baseplates. The results fully confirmed the conclusions in the Paper so that, provided precautions were taken to reduce shock loads on the motors, particularly the commutators, it would appear that the less expensive arrangement incorporating axle-hung motors was quite justified.

58. Mr Kibblewhite, whose interest was also in electric rolling stock, mentioned that the savings per locomotive were appreciable; and since most of the track over which the locomotives on British Railways run was continuous-welded, it would be surprising if the evidence at the end of 1966 to which he referred was unfavourable.

59. Mr Fouvy's suggestions for further work with the load-measuring baseplates were interesting and the Author assured him that the baseplates were proving to be a most useful and adaptable tool.

60. $\mathrm{Mr}$ Gelson raised a big subject when he referred to the continuously varying transfer of load between wheels; this could be due to track features as well as to the parasitic movements of the rolling stock. The Author confirmed that load-measuring baseplates would have to be used on many more than six sleepers to detect such changes and, even then, the method would be cumbersome and tedious. A better method would be to use strain-gauged wheels ${ }^{3,4,5}$ which had been developed quite successfully in the last few years.

61. The only procedure known to the Author for establishing the effects of a close, adjacent axle was that described in $\S 15$ and Fig. 5 of the Paper. The influence lines at any track irregularity such as a rail joint might not be symmetrical and, for that reason. the Author had not presented or used any results which necessitated such procedure.

62. The Author did not agree with Mr Gelson that the method of determining the stiffness of track beds described in the Paper lead to values considerably greater than the truth though it usually lead to values higher than the method of measuring the depressions of all sleepers carrying the load. The load-measuring baseplate on the sleeper under consideration measured only the load imposed on that sleeper; and the formation halfway between sleepers at a depth of 4 feet was not materially affected by the loading of the sleepers. The resulting graphs, e.g. Fig. 10, gave a complete and truthful picture.

63. In contrast, the empirical method of measuring the depression of all loaded sleepers almost certainly involved some sleepers which were not perfectly packed and several only lightly loaded; and the lower true values of stiffness obtained at low loads (see Fig. 10) would predominate.

\section{ReFERENCES}

2. Department of Scientific and Industrial Research. Report of the Bridge Stress Committee. H.M.S.O., London, 1928. 
3. Olson P. E. and Johnsson S. Seitenkräfte zwischen Rad und Scheine. Eine experimentelle Untersuchung. (Lateral forces between wheel and rail. An experimental investigation.) Glasers Annln Gewerbe Bauw. May 1959, pp. 153-161.

4. ZotTmanN W. Messung der während der Fahrt auf ein Eisenbahnrad wirkenden Kräfte. (Measurement of the forces exerted on a running railway wheel.) Glasers Annln Gewerbe Bauw. April 1961, pp. 115-123.

5. Weber H. H. Zur direkten Messung der Kräfte zwischen Rad und Schiene. (The direct measurement of the forces between wheel and rail.) Elektrische Bahnen, May 1961, pp. 93-110 and Glasers Annln Gewerbe Bauw. July 1961, pp. 236-244. 